\title{
Nonstented tubularized incised plate urethroplasty with Y-to-I spongioplasty in non-toilet trained children
}

\author{
Fayez Almodhen, MD; Ahmed Alzahrani, MD; Roman Jednak, MD; Jean Paul Capolicchio, MD; \\ Mohamed T. El Sherbiny, MD
}

See related article on page 115

\begin{abstract}
Introduction: This study was designed to evaluate the supportive role of spongioplasty during tubularized incised plate (TIP) urethroplasty repair of hypospadias.

Methods: All non-toilet trained children who underwent TIP repair for primary hypospadias by 1 surgeon over a 30-month period were included in our study. The divergent spongiosa was mobilized off the corpora cavernosa and was rotated toward the midline to wrap the neourethra. A dartos flap was used to cover the neourethra. The neourethra was calibrated immediately after surgery in all patients. A urethral stent was left in place only when difficult calibration was encountered. Complications and cosmetic appearance were documented at last follow-up.
\end{abstract}

Results: Thirty-two consecutive patients with a mean age of 18 (standard deviation [SD] 6) months were included in the study. The defects were distal and mid-shaft in 26 patients $(81.3 \%)$ and proximal-shaft in $6(18.8 \%)$. No intraoperative catheterization difficulties were encountered and all repairs were nonstented. Antibiotics and anticholinergics were not required. Mean follow-up was 9 (SD 6) months. Urinary extravasation developed in 1 patient (3.1\%) on the second postoperative day. A urethral catheter was easily inserted and left indwelling for 5 days. One patient presented 6 days postoperatively with suspected voiding difficulty. Urethral calibration was easily performed excluding any mechanical obstruction. There were no urinary fistulae and reoperation was not required. An excellent cosmetic appearance was achieved in all patients.

Conclusion: TIP urethroplasty is a versatile operation that can be performed in almost all cases of penile hypospadias. A nonstented technique for hypospadias repair simplifies postoperative care and obviates the need for antibiotics and anticholinergics. We believe that spongioplasty provides good support to the neourethra and the hypoplastic distal urethra that may facilitate catheterization in the immediate and early postoperative periods, if required. Future controlled study is warranted to further evaluate the role of spongioplasty.

CUAJ 2008;2(2):110-4

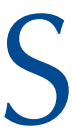
everal authors have reported excellent results with a stent-free tubularized incised plate (TIP) urethroplasty repair without an increase in the complication rate. ${ }^{1-4}$ However, early postoperative urinary retention occurs in $2 \%-24 \%$ of patients. ${ }^{3,5,6}$ In such cases, urethral catheterization is discouraged, as it is believed to increase the risk of fistula formation. Suprapubic catheter placement has been recommended as the preferred treatment. ${ }^{3}$ This may necessitate another anesthetic and may add the risk of hematuria secondary to inadvertent bladder mucosal injury. The risk of urinary retention has led some surgeons to continue using stents during TIP repairs.

Y-to-I wrap spongioplasty has been shown to recreate a nearly normal urethra in most cases. ${ }^{7}$ We hypothesized that spongioplasty can provide sufficient urethral support to withstand early urethral catheterization without compromising the repair. This study was designed to evaluate the supportive role of spongioplasty during TIP repair for various degrees of penile hypospadias.

\section{Methods}

All non-toilet trained children who underwent TIP repair for primary hypospadias by 1 surgeon between February 2004 and August 2006 were included in our study. Patients with glanular and coronal hypospadias and a mobile urethra had meatal advancement procedures and were excluded from our study. Moreover, a standard staged repair or a 1-stage procedure using a local skin flap was preferred for patients with severe forms of hypospadias, severe curvature, a short penis or a severely dysplastic urethral plate. As such these patients were also excluded from the study.

Optical magnification was used for all procedures. The surgical technique was similar to that described previously by Snodgrass. ${ }^{8} \mathrm{~A}$ bloodless field was maintained during surgery with a penile tourniquet. An artificial 
erection was induced to confirm a straight penis as necessary.

The surgical technique for spongioplasty was similar to that described previously by Yerkes and colleagues. ${ }^{7}$ In all cases, the divergent spongiosa was mobilized off the corpora cavernosa on both sides of the urethral plate (Fig. 1). The spongiosal dissection started well proximal to the hypospadiac meatus and began at the origin of the hypoplastic distal urethra. We found it easier to develop the proper plane of dissection before applying the tourniquet. Mobilization of the spongiosa was continued distally beneath the urethral plate. The distal portions of the spongiosa were then detached from the glans and the glanular wings were developed. Oblique rather than perpendicular lateral incisions along the edges of the urethral plate were performed to maintain healthy intact spongiosa around the plate distally. The central incision of the urethral plate was performed in the standard fashion. Care was taken not to make a hole in the urethral plate while making the central relaxing incision. Urethroplasty was performed using double-layered subcuticular $7 / 0$ polyglactin running sutures (Fig. 2). The spongiosa were then rotated toward the midline to wrap the neourethra

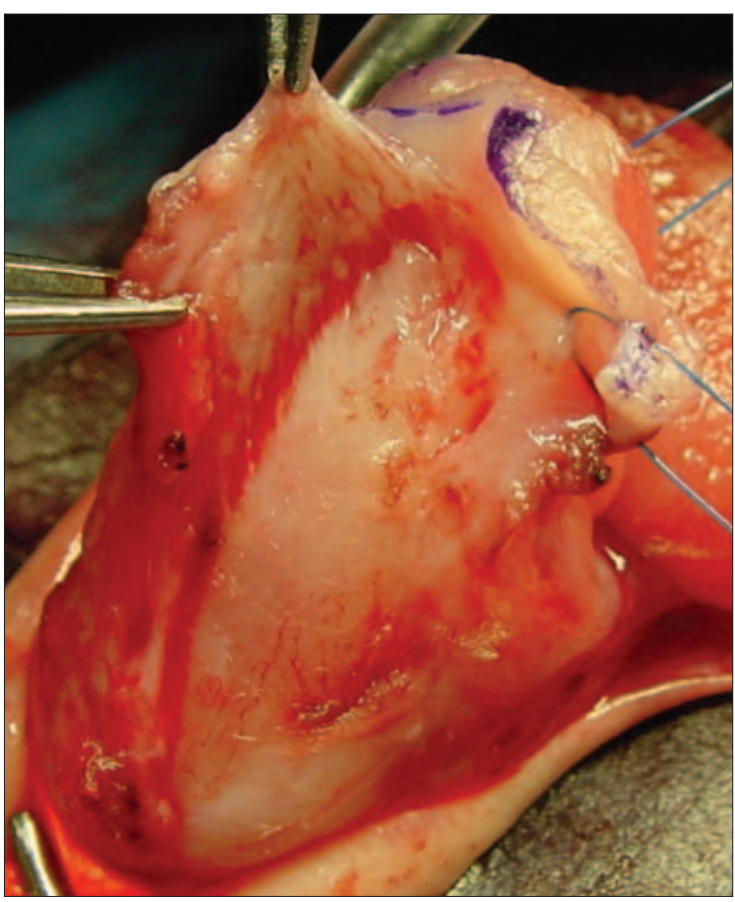

Fig. 1. The spongiosa is mobilized off the corpora cavernosa, the distal portions of the spongiosa are detached from the glans and the glanular wing is developed. as well as the hypoplastic portion of the native urethra (Fig. 3). A dartos flap mobilized from the dorsal prepuce was then used to cover the neourethra in all patients.

After the procedure the urethroplasty was cal-

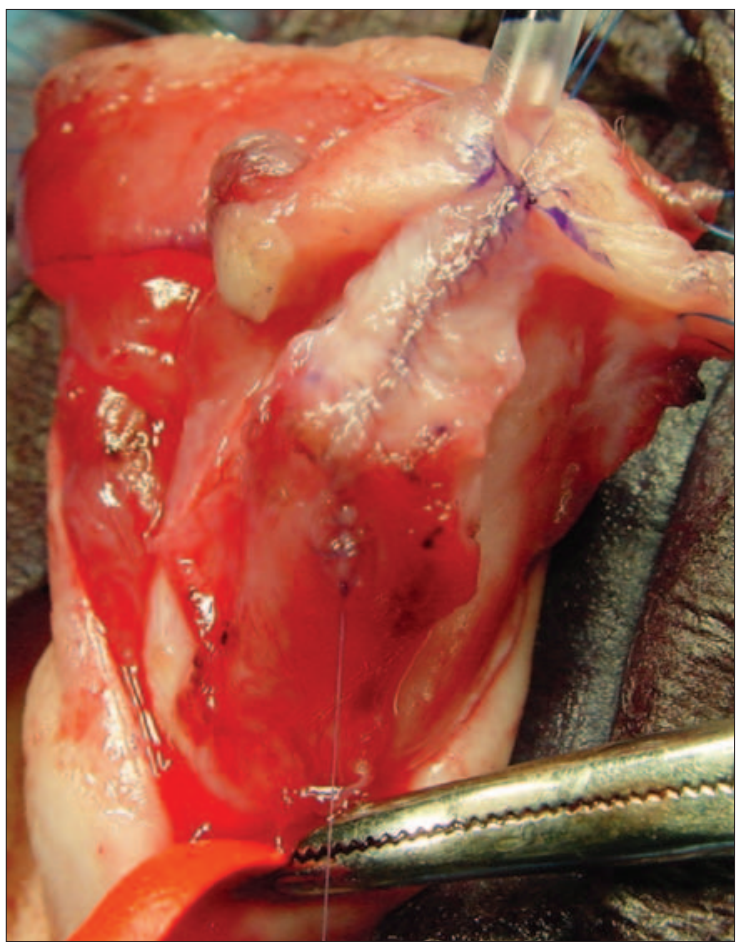

Fig. 2. Urethroplasty is performed without any tension using subcuticular $7 / 0$ polyglactin running sutures. Note the previous mobilization of the divergent spongiosa makes the midline urethroplasty tension-free.

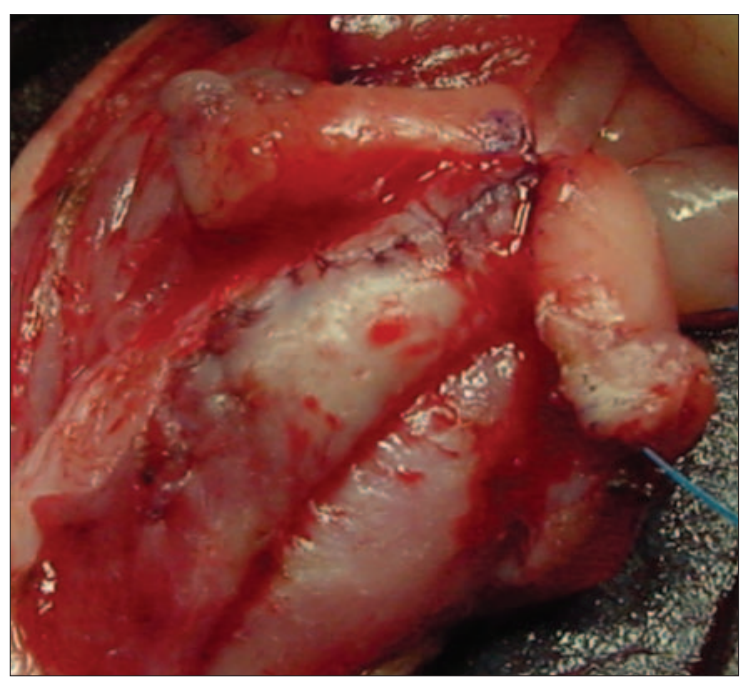

Fig. 3. The spongiosa are rotated toward the midline to wrap the neourethra as well as the hypoplastic portion of the native urethra. 
ibrated with an 8-F catheter. If the catheter passed easily, the bladder was drained and a stent was not left. When difficulty was encountered, a urethral stent was left in place. A circumferential Tegaderm (3M, St. Paul, Minnesota) dressing was applied in all cases. Patients were discharged on the same day of surgery with a prescription for acetaminophen and codeine. Prophylactic antibiotics and oxybutynin were prescribed only in patients with indwelling stents.

Follow-up consisted of a first visit at 3-4 weeks, a second visit at 3-6 months and further visits only when necessary. Complications as well as overall cosmetic appearances were recorded at the last follow-up.

\section{Results}

Our study included 32 consecutive patients with a mean age of 18 (standard deviation [SD] 6) months (range 7-29 mo). The defects were distaland midshaft in 26 patients (81.3\%) and proximalshaft in 6 (18.8\%). Adjunctive intraoperative analgesia consisted of epidural anesthesia (30 patients) or a penile block (2 patients). Penile chordee requiring dorsal tunica albuginea plication was found in 10 patients $(31.3 \%)$, all of whom had proximal-shaft hypospadias. A hypoplastic distal urethra (length 7.5 [SD 5] mm, range 5-20 mm) was found in 14 patients (43.8\%).

No difficulty was encountered during intraoperative catheterization and all repairs were left nonstented. Antibiotics and anticholinergics were not required. Mean follow-up was 9 (SD 6) months. Pain medications were required for a mean duration of 2 (SD 1) days. Urinary extravasation developed in 1 patient $(3.1 \%)$ on the second postoperative day. A urethral catheter was easily inserted and left indwelling for 5 days. One patient presented with suspected voiding difficulty 6 days after surgery. Urethral calibration was easily performed thereby excluding a mechanical obstruction. One patient $(3.1 \%)$ developed acute pyelonephritis 4 months postoperatively and was found to have a meatal stenosis. An office meatotomy was performed using a topical anesthetic cream. There were no urinary fistulae and reoperation was not required. An excellent cosmetic appearance with a vertical slit meatus on the tip of a conical glans was obtained in all patients.

\section{Discussion}

In the year 2000, Yerks and colleagues described the Y-to-I wrap technique where the spongiosa were separated from the corpora cavernosa on both sides of the urethral plate and wrapped around various forms of 1-stage urethroplasty, including the TIP repair. ${ }^{7}$ Excellent results were achieved and the procedure was suggested as an alternative to the dartos flap. In the same year, investigators from France described a similar procedure, ${ }^{9-11}$ coining the term "spongioplasty." Dodat and colleagues ${ }^{12}$ introduced a modified version of the spongioplasty technique in which the spongiosa were separated from the corpora cavernosa as well as from the urethral plate and then used as an intervening layer to cover the neourethra. The technique has since gained popularity and has been adopted by other surgeons with variable rates of success. ${ }^{8,13}$ The reported fistula rate with this technique ranges from $0 \%$ to $31 \%$. While several investigators have shown spongioplasty to be as protective as a dartos flap, ${ }^{7,12,13}$ others have found that spongioplasty is associated with unacceptably high fistula rates when compared with the standard dartos flap. ${ }^{14}$

The variable rate of success may be explained at least in part by variations in spongiosal anatomy. In some cases the spongiosa are prominent and allow for an overlapping closure in a vest over pants fashion. In others cases spongioplasty can be performed only using a midline closure thereby creating 2 opposing suture lines. The latter situation could be the predisposing cause of fistula formation in some series. We found that no patient in our series developed a fistula when spongioplasty was combined with dartos flap coverage of the repair. In addition, several of the patients included in our study who underwent a stentless TIP repair had mid- and proximal-penile shaft hypospadias. Limitations of our study included the limited number of cases and the lack of a control group. We speculate that the role of spongioplasty in minimizing fistula formation could be related to the decreased tension on the midline urethroplasty suture line especially during erection. The dartos flap additionally prevents opposing suture lines. A similar fistula rate has been previously reported using a dartos flap alone without spongioplasty. ${ }^{4}$ Future controlled study is warranted to further evaluate the role of spongioplasty in 
minimizing the rate of fistula. Because of the variation of spongiosal anatomy, we continue using the standard dartos flap with spongioplasty to maximize protection of the neourethra.

It has been suggested that spongioplasty can be useful in minimizing penile chordee. ${ }^{7,12} \mathrm{We}$ found chordee correction required dorsal tunica albuginea plication in $31.3 \%$ of our patients. This may be partially explained by the fact that a number of our included cases had mid- and posterior penile hypospadias. Furthermore, we feel that curvature secondary to corporal disproportion generally requires dorsal plication. Although spongioplasty may be useful for the correction of mild degrees of curvature, dorsal plication or ventral grafting will still be necessary in more severe cases.

Hypospadias repair without postoperative stenting is associated with a short hospital stay, lower risk of infection and no bladder spasm. Furthermore, indwelling catheters require special care to avoid accidental displacement or inadvertent pressure on the neourethra. Nevertheless, a stent-free repair may increase the incidence of urinary retention and extravasation following surgery. Urinary retention has been reported in $2 \%-30 \%$ of patients following unstented hypospadias repair. ${ }^{3,5,6}$ An important additional advantage of spongioplasty is the construction of a urethra of nearly normal structure.? In our study, we show that spongioplasty provides good support to the neourethra and immediate postoperative catheterization was successful in all patients as well as early postoperative catheterization in the 2 patients who presented with complications. Even in the presence of extravasation, urethral catheterization was possible without difficulty or long-term complications. It is believed that in this single case of extravasation, an unrecognized small perforation was made while centrally incising the urethral plate. Consequently, we carefully inspect the back of the urethral plate to detect small perforations and repair them if necessary. We feel that it is prudent to leave a stent in cases with a known urethral perforation.

Significant thinning of the distal urethra has been noted in $23.4 \%$ of cases of primary hypospadias. ${ }^{15}$ Preserving the thin distal urethra has been recommended to simplify the operative procedure without compromising the surgical results of the TIP repair. This technique, which incorporates a thin, relatively avascular mucosa in hypospadias repair, has been criticized. ${ }^{16}$ In our study, a hypoplastic distal urethra of a mean length of 7.5 (SD 5) $\mathrm{mm}$ was found in 14 patients (43.8\%). Although we preserved the thin distal urethra in these patients, it was covered by the divergent spongiosal tissue in all cases. The spongioplasty provides support to the thin urethra that can prevent diverticula and facilitate catheterization if required.

Although the technique described in this series involves mobilization of the corpora spongiosa, postoperative pain was similar to that seen for other types of urological surgery. Pain control was achieved by the usual regimen of acetaminophen and codeine for a mean duration of 2 days. ${ }^{4}$ Since a stent was not left in place, antibiotics and anticholinergics were not prescribed.

\section{Conclusion}

TIP repair is a versatile operation that can be performed in almost all cases of penile hypospadias. A nonstented technique for hypospadias repair simplifies postoperative care and obviates the need for antibiotics and anticholinergics. We believe that spongioplasty provides good support to the neourethra and the hypoplastic distal urethra that may facilitate catheterization in the immediate and early postoperative periods, if required. Future controlled study is warranted to further evaluate the role of spongioplasty.

From the Montreal Children's Hospital, McGill University, Montréal, Que.

This article has been peer reviewed.

Competing interests: None declared.

\section{References}

1. Rabinowitz R. Outpatient catheterless modified Mathieu hypospadias repair. J Urol 1987; 138:1074-6.

2. Hakim $S$, Merguerian PA, Rabinowitz $R$, et al. Outcome analysis of the modified Mathieu hypospadias repair: comparison of stented and unstented repairs. J Urol 1996; 156:836-8.

3. Leclair MD, Camby C, Battisti S, et al. Unstented tubularized incised plate urethroplasty combined with foreskin reconstruction for distal hypospadias. Eur Urol 2004;46: 526-30.

4. Steckler RE, Zaontz MR. Stent-free Thiersch-Duplay hypospadias repair with the Snodgrass modification. J Urol 1997;158:1178-80.

5. Buson H, Smiley D, Reinberg Y, et al. Distal hypospadias repair without stents: Is it better? J Urol 1994;151:1059-60.

6. El-Sherbiny MT. Tubularized incised plate repair of distal hypospadias in toile-trrained 
children: Should a stent be left? BJU Int 2003;92:1003-5.

7. Yerkes EB, Adams $M C$, Miller DA, et al. Y-to-I wrap: use of the distal spongiosum for hypospadias repair. J Urol 2000;163:1536-8; discussion 1538-9.

8. Snodgrass WT. Tubularized incised plate (TIP) hypospadias repair. Urol Clin North Am 2002;29:285-90.

9. Beaudoin S, Delaage PH, Bargy F. Anatomical basis of surgical repair of hypospadias by spongioplasty. Surg Radiol Anat 2000;22:139-41.

10. Delaage PH, Bargy F, Beaudoin S. Spongioplasty in the treatment of hypospadias. Prog Urol 2005; 15:1120-3

11. Mezzine S, Beaudoin S, Bargy F. Medium and long-term evaluation of spongioplasty in hypospadias repair. Prog Urol 2005;15:519-23.

12. Dodat H, Landry JL, Szwarc C, et al. Spongioplasty and separation of the corpora cavernosa for hypospadias repair. BJU Int 2003;91:528-31.

13. El-Sherbiny MT, Hafez AT, Dawaba MS, et al. Comprehensive analysis of tubularized incised-plate urethroplasty in primary and re-operative hypospadias. BJU Int 2004; 93:1057-61.

14. Kocvara R, Dvoracek J, Dite Z, et al. Comprehensive long-term analysis of hypospadias repair using vascularized flaps and tubularized incized plates - report on 588 cases. Cas Lek Cesk 2005;144(Suppl 2):7-11.

15. Yang SS, Chen YT, Hsieh CH, et al. Preservation of the thin distal urethra in hypospadias repair. J Urol 2000;164:151-3.

16. Elbakry A. Re: Preservation of the thin distal urethra in hypospadias repair. J Urol 2001; 165:543-4.

Correspondence: Dr. Mohamed T. El Sherbiny, Assistant Professor of Urology, McGill University, C527-2300 rue Tupper, Montréal QC H3H 1P3; elsherbi@yahoo.com

\section{Prostate Cancer Research Foundation of Canada The Scientific and Medical Advisory Committee Executive effective June 2008}

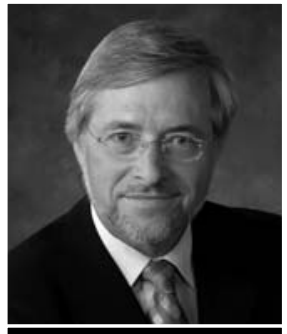

Dr. Yves Fradet MD FRCSC, Chair

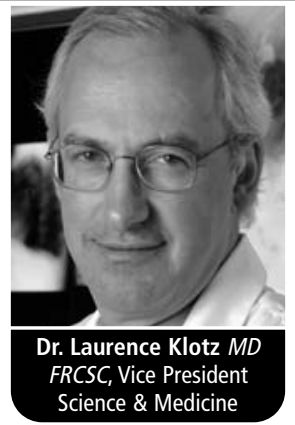

The Prostate Cancer Research Foundation of Canada is pleased to announce the addition of eight distinguished experts to its Scientific and Medical Advisory Committee: Dr. Mario Chevrette PhD, Dr. James Davie PhD, Dr. Emma Guns PhD, Dr. Pierre Karakiewicz MD FRCSC, Dr. Jeffrey Medin PhD, Dr. Robert Nam MD FRCSC, Dr. Alan So MD FRCSC and Dr. Vasundara Venkateswaran PhD.

These scientists join the Executive, pictured above, and the following members: Dr. Armen Aprikian MD FRCSC, Dr. David Bell MD FRCSC,
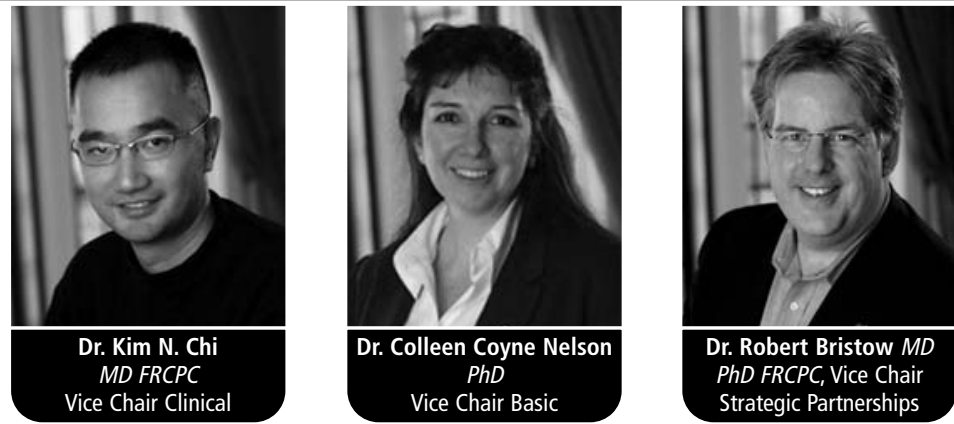

Dr. Michael Chetner MD FRCSC, Dr. Bryan Donnelly MB FRCS, Dr. Neil Fleshner MD FRCSC, Dr. Gerardo Ferbeyre MD PhD, Dr. Masoom Haider MD, Dr. Rama Khokha PhD, Dr. Theo Van der Kwast MD PhD, Dr. Chris Morash MD FRCSC, Dr. Matthew Bruce Parliament MD FRCPC, Dr. Michael Pollak MD FRCPC, Dr. Jackson Wu MD FRCPC and Science Officer, Dr. Michael Fraser PhD.

The Prostate Cancer Research Foundation of Canada is the leading national organization dedicated solely to eliminating the threat of prostate cancer. For more information, visit www.prostatecancer.ca

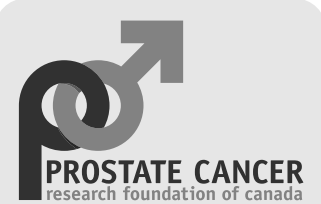
LE CANCER DE LA PROSTATE
PROSTATE CANCER 